\title{
Sex Difference of Venous Thromboembolism Risk in Chronic Obstructive Pulmonary Disease and Interstitial Lung Disease
}

\author{
Yong Shik Kwon, ${ }^{1}$ Won-II Choi, ${ }^{1 *}$ Choong Won Lee, ${ }_{1}^{2}$ Junshik Hong, Juhyun Lee, ${ }^{4}$ Soo-Mee Bang ${ }^{4}$ \\ ${ }^{1}$ Department of Internal Medicine, Keimyung University Dongsan Medical Center, Daegu, Korea \\ 2Department of Occupational \& Environmental Medicine, Sungso Hospital, Andong, Korea \\ ${ }^{3}$ Department of Internal Medicine, Seoul National University College of Medicine, Seoul National University Hospital, Seoul, Korea \\ ${ }^{4}$ Department of Internal Medicine, Seoul National University College of Medicine, Seoul National University Bundang Hospital, Seongnam, Korea
}

Received: 4 September 2017 Revised: 25 November 2017 Accepted: 27 November 2017

*Corresponding author: Won-II Choi, MD

Department of Internal Medicine, Keimyung University School of

Medicine, 56 Dalseong-ro, Jung-gu

Daegu 41931, Korea

Tel: +82-53-250-7572

Fax: +82-53-250-7434

E-mail:wichoi@dsmc.or.kr

Source of funding: This work was supported by a grant (KSTH 2016-002) from the Korean Society on Thrombosis and Hemostasis.
Copyright (C) Korean Society on Thrombosis and Hemostasis. All rights reserved.
Purpose: Sex may have an influence on the prevalence of venous thromboembolism (VTE) as well as chronic lung disease. We aimed to explore the role of sex in relation to the prevalence of pulmonary embolism (PE) and deep vein thrombosis (DVT) in patients with chronic obstructive pulmonary disease (COPD), interstitial lung disease (ILD), and rheumatoid arthritis (RA).

Methods: We evaluated the VTE prevalence associated with COPD, ILD, and RA, using data from the Korean Health Insurance Review and Assessment Service, from January 2013 to December 2013, which included 40,593,174 ( $\geq 20$ years), Korean residents. The number of patients with COPD, ILD, and RA was $222,130,20,946$, and 89,280, respectively. The patients were identified as having COPD, ILD, or RA based on the International Classification of Disease-10 diagnostic codes.

Results: Risk of DVT in women had a 0.71-fold (95\% confidence interval [CI], 0.40-1.25) lower than men with RA. Risk of DVT in women had a $2.41(95 \% \mathrm{Cl}, 1.93-2.99)$, 2.75-fold $(95 \% \mathrm{Cl}, 1.08-6.99)$ higher men with COPD and ILD, respectively. Risk of PE in women had a 0.70 -fold $(95 \% \mathrm{Cl}, 0.39-1.25)$ lower than men with RA. Risk of PE in women had a $2.57(95 \% \mathrm{Cl}, 2.25-2.93), 1.85(95 \% \mathrm{Cl}, 1.24-2.75)$-fold higher than men with COPD and ILD, respectively.

Conclusion: A significantly higher prevalence of PE and DVT was observed in women, than men, with COPD and ILD. No significant difference was found in the prevalence of PE and DVT in the case of RA, between men and women.

Keywords: Chronic obstructive pulmonary disease, Interstitial lung disease, Rheumatoid arthritis, Pulmonary embolism, Deep vein thrombosis, Prevalence

\section{Introduction}

Venous thromboembolism is a significant disorder with a reported incidence of from 16 to 100 per 100,000 population per individuals in many countries. ${ }^{1,2}$ Overall incidence of first venous thromboembolism was similar between men and women. ${ }^{1,3}$ However, the incidence of first venous thromboembolism in men is higher than women without reproductive risk factors. ${ }^{4}$

Risk of venous thromboembolism is higher among women who had reproductive risk factor like prescribed oral contraceptives and pregnancy in same age group. ${ }^{5}$ In recurrent venous thromboembolism, men had about a 50\% higher risk than women when anticoagulation was discontinued. ${ }^{6}$ Including sex difference in venous thromboembolism, the risk factor of venous embolism was focused on increasing age, malignant neoplasm, surgery, immobilization, cardiorespiratory failure, the presence of central venous line, estrogen and inherited hematologic condition.?

Chronic lung diseases including chronic obstructive lung disease, interstitial lung disease, bronchiectasis were 1.23-fold higher risk of developing a pulmonary embolism (PE) or deep vein thrombosis (DVT) than without chronic lung diseases. ${ }^{8}$ Additionally, the sex difference in susceptibility to the lung damage in chronic obstructive lung disease and to the influence of severity of some lung disease was identified. ${ }^{910}$ However, in patients of with chronic lung diseases, the sex difference in the occurrence of venous thromboembolism is uncertain.

Identification of risk scale for venous thromboembolism among men and women with specific diseases can help to identify those who will need treatment or prevention of thromboembolism.

Sex with the specific respiratory disease may have an influence on the prevalence of venous thromboembolism (VTE). We aimed to explore the role of sex in relation to the prevalence of PE and DVT in patients with chronic obstructive pulmonary disease (COPD), interstitial lung disease (ILD), and rheumatoid arthritis (RA).

\section{Methods}

Study subjects

This was a retrospective cohort study based on data collected from the national database of the Korean Health Insurance Review and Assessment Service (HIRA). HIRA is a government-affiliated organization that builds an accurate claims review and is a quality assessment system for the National Health Insurance (NHI). The NHI is the only public medical insurance system operated by the Ministry of Health and Welfare, in Korea. ${ }^{11,12}$

Patients with RA, ILD, or COPD were identified based on the In- 
ternational Classification of Disease-10 (ICD-10) diagnostic codes.

This study adhered to the Declaration of Helsinki and was approved by the institutional review board of Dongsan Hospital, Keimyung University School of Medicine. Informed consent was not obtained because the patients' data were anonymized.

\section{Case identification}

According to the National Statistical Office of Korea, the mid-year population size of people aged $\geq 20$ years, in 2013, was 40,593,174. Patients were included in the study based on the ICD-10 diagnostic code for ILD (J84). ICD-10 diagnostic codes are used as a reference for the medical diagnosis of diseases and within the health insurance system. We used J44 for the identification of obstructive pulmonary disease, and M05 for RA. We excluded patients who fit the definitions of two or more codes, from among RA, ILD, and COPD.

The codes used for the identification of DVT included I80.2 (DVT, not otherwise specified [NOS]) and I80.3 (embolism or thrombosis of the lower extremity, NOS). The codes used for PE included I26 (pulmonary thromboembolism), I26.0 (PE with mention of acute cor pulmonale), and I26.9 (PE, NOS). I82 was used for the identification of other forms of venous embolism or thrombosis. Cases that

Table 1. Sex distribution of pulmonary embolism and deep vein thrombosis prevalence in the Korean national population

\begin{tabular}{|c|c|c|c|c|c|c|c|c|}
\hline \multirow{2}{*}{ Group } & \multicolumn{4}{|c|}{ Men } & \multicolumn{4}{|c|}{ Women } \\
\hline & Population & Cases & Prevalence & $95 \% \mathrm{Cl}$ & Population & Cases & Prevalence & $95 \% \mathrm{Cl}$ \\
\hline \multicolumn{9}{|c|}{ Prevalence of deep vein thrombosis $(1 / 100,000)$} \\
\hline General population & $20,129,689$ & 5,118 & 25.4 & 24.7-26.1 & $20,463,485$ & 6,250 & 30.5 & 29.8-31.3 \\
\hline RA & 16,917 & 16 & 94.6 & $48.3-140.9$ & 72,363 & 49 & 67.7 & 48.8-86.7 \\
\hline COPD & 146,339 & 148 & 101.1 & $84.8-117.4$ & 73,128 & 178 & 243.4 & 207.7-279.1 \\
\hline ILD & 12,725 & 7 & 55.0 & 14.3-95.8 & 7,928 & 12 & 151.4 & $65.8-236.9$ \\
\hline \multicolumn{9}{|c|}{ Prevalence of pulmonary embolism $(1 / 100,000)$} \\
\hline General population & $20,129,689$ & 2,639 & 13.1 & $12.6-13.6$ & $20,463,485$ & 3,671 & 17.9 & $17.4-18.5$ \\
\hline RA & 16,917 & 15 & 88.7 & 43.8-133.5 & 72,363 & 45 & 62.2 & $44.0-80.4$ \\
\hline COPD & 146,339 & 400 & 273.3 & 246.6-300.1 & 73,128 & 512 & 700.1 & 639.7-760.6 \\
\hline ILD & 12,725 & 46 & 361.5 & $257.2-465.8$ & 7,928 & 53 & 668.5 & 489.1-847.9 \\
\hline
\end{tabular}

Between January 2013 and December 2013. Summarized based on the diagnosis at the top of the list of the International Statistical Classification of Diseases and Related Health Problems, 10th edition (ICD-10) codes of respiratory diseases.

ILD, interstitial lung disease; COPD, chronic obstructive pulmonary disease; RA, rheumatoid arthritis.

Table 2. Risk of sex in deep vein thrombosis and pulmonary embolism in the Korean national population in general population and patients with interstitial lung disease, chronic obstructive pulmonary disease, and rheumatoid arthritis

\begin{tabular}{|c|c|c|c|c|c|c|c|}
\hline Group & & Women (n) & Men (n) & OR & $95 \% \mathrm{Cl}$ & $\chi^{2}$ & $P$-value \\
\hline \multicolumn{8}{|l|}{ Deep vein thrombosis } \\
\hline \multirow[t]{2}{*}{ General population } & Yes & 6,250 & 5,118 & & & & \\
\hline & No & $20,457,235$ & $20,124,571$ & 1.20 & $1.15-1.24$ & 94.90 & $<0.01$ \\
\hline \multirow[t]{2}{*}{ RA } & Yes & 49 & 16 & & & & \\
\hline & No & 72,314 & 16,901 & 0.71 & $0.40-1.25$ & 1.36 & 0.24 \\
\hline \multirow[t]{2}{*}{ COPD } & Yes & 178 & 148 & & & & \\
\hline & No & 72,950 & 146,191 & 2.41 & $1.93-2.99$ & 66.54 & $<0.01$ \\
\hline \multirow[t]{2}{*}{ ILD } & Yes & 12 & 7 & & & & \\
\hline & No & 7,916 & 12,718 & 2.75 & $1.08-6.99$ & 4.91 & 0.02 \\
\hline \multicolumn{8}{|l|}{ Pulmonary embolism } \\
\hline \multirow[t]{2}{*}{ General population } & Yes & 3,671 & 2,639 & & & & \\
\hline & No & $20,459,814$ & $20,127,050$ & 1.36 & $1.30-1.43$ & 152.27 & $<0.01$ \\
\hline \multirow[t]{2}{*}{ RA } & Yes & 45 & 15 & & & & \\
\hline & No & 72,318 & 16,902 & 0.70 & $0.39-1.25$ & 1.43 & 0.23 \\
\hline \multirow[t]{2}{*}{ COPD } & Yes & 512 & 400 & & & & \\
\hline & No & 72,616 & 145,939 & 2.57 & $2.25-2.93$ & 214.64 & $<0.01$ \\
\hline \multirow[t]{2}{*}{ ILD } & Yes & 53 & 46 & & & & \\
\hline & No & 7,875 & 12,679 & 1.85 & $1.24-2.75$ & 9.65 & $<0.01$ \\
\hline
\end{tabular}

Between January 2013 and December 2013. Summarized based on the diagnosis at the top of the list of the International Statistical Classification of Diseases and Related Health Problems, 10th edition (ICD-10) codes of respiratory diseases.

$\mathrm{OR}$, odds ratio; $\mathrm{Cl}$, confidence intervals; ILD, interstitial lung disease; COPD, chronic obstructive pulmonary disease; RA, rheumatoid arthritis. 
Table 3. Risk of age and sex in deep vein thrombosis prevalence in the Korean national population and patients with interstitial lung disease, chronic obstructive pulmonary disease, and rheumatoid arthritis

\begin{tabular}{|c|c|c|c|c|c|c|c|}
\hline \multicolumn{2}{|l|}{ Group } & Women (n) & Men (n) & OR & $95 \% \mathrm{Cl}$ & $\chi^{2}$ & $P$-value \\
\hline \multicolumn{8}{|c|}{ General population } \\
\hline \multirow[t]{2}{*}{$20-29$} & Yes & 75 & 99 & & & & \\
\hline & No & $3,209,306$ & $3,557,137$ & 0.83 & $0.62-1.13$ & 1.30 & 0.25 \\
\hline \multirow[t]{2}{*}{$30-39$} & Yes & 205 & 238 & & & & \\
\hline & No & $3,969,304$ & $4,177,929$ & 0.90 & $0.75-1.09$ & 1.05 & 0.30 \\
\hline \multirow[t]{2}{*}{$40-49$} & Yes & 401 & 458 & & & & \\
\hline & No & $4,399,717$ & $4,554,054$ & 0.90 & $0.79-1.03$ & 2.07 & 0.14 \\
\hline \multirow[t]{2}{*}{$50-59$} & Yes & 743 & 952 & & & & \\
\hline & No & 3,995,189 & $4,044,882$ & 0.79 & $0.71-0.86$ & 23.24 & $<0.01$ \\
\hline \multirow[t]{2}{*}{$60-69$} & Yes & 1,352 & 1,281 & & & & \\
\hline & No & 2,304,387 & $2,159,459$ & 0.98 & $0.91-1.06$ & 0.07 & 0.77 \\
\hline \multirow[t]{2}{*}{$70-79$} & Yes & 2,185 & 1,477 & & & & \\
\hline & No & $1,763,515$ & $1,289,234$ & 1.08 & $1.01-1.15$ & 5.40 & 0.02 \\
\hline \multirow[t]{2}{*}{$80+$} & Yes & 1,289 & 613 & & & & \\
\hline & No & 815,817 & 341,876 & 0.88 & $0.80-0.97$ & 6.64 & $<0.01$ \\
\hline \multicolumn{8}{|l|}{ RA } \\
\hline \multirow[t]{2}{*}{$20-29$} & Yes & 2 & 0 & & & & \\
\hline & No & 1,597 & 292 & & & & \\
\hline \multirow[t]{2}{*}{$30-39$} & Yes & 1 & 1 & & & & \\
\hline & No & 6,190 & 976 & 0.15 & $0.00-2.52$ & 2.24 & 0.13 \\
\hline \multirow[t]{2}{*}{$40-49$} & Yes & 8 & 1 & & & & \\
\hline & No & 14,062 & 2,419 & 1.37 & $0.17-11.00$ & 0.09 & 0.76 \\
\hline \multirow[t]{2}{*}{$50-59$} & Yes & 29 & 7 & & & & \\
\hline & No & 23,415 & 4,729 & 0.83 & $0.36-1.91$ & 0.17 & 0.67 \\
\hline \multirow[t]{2}{*}{$60-69$} & Yes & 34 & 16 & & & & \\
\hline & No & 18,121 & 5,224 & 0.61 & $0.33-1.11$ & 2.65 & 0.10 \\
\hline \multirow[t]{2}{*}{$70-79$} & Yes & 53 & 11 & & & & \\
\hline & No & 11,298 & 3,619 & 1.54 & $0.80-2.95$ & 1.73 & 0.18 \\
\hline \multirow[t]{2}{*}{$80+$} & Yes & 13 & 7 & & & & \\
\hline & No & 2,144 & 585 & 0.50 & $0.20-1.27$ & 2.16 & 0.14 \\
\hline \multicolumn{8}{|l|}{ COPD } \\
\hline \multirow[t]{2}{*}{$20-29$} & Yes & 1 & 1 & & & & \\
\hline & No & 1,015 & 993 & 0.97 & $0.06-15.66$ & 0.00 & 0.98 \\
\hline \multirow[t]{2}{*}{$30-39$} & Yes & 4 & 5 & & & & \\
\hline & No & 1,970 & 2,237 & 0.90 & $0.24-3.38$ & 0.02 & 0.88 \\
\hline $40-49$ & Yes & 5 & 9 & & & & \\
\hline & No & 4,116 & 5,505 & 0.74 & $0.24-2.21$ & 0.28 & 0.59 \\
\hline $50-59$ & Yes & 30 & 67 & & & & \\
\hline & No & 10,918 & 18,849 & 0.77 & $0.50-1.18$ & 1.37 & 0.24 \\
\hline $60-69$ & Yes & 108 & 196 & & & & \\
\hline & No & 15,839 & 41,839 & 1.45 & $1.15-1.84$ & 9.86 & $<0.01$ \\
\hline 70-79 & Yes & 274 & 409 & & & & \\
\hline & No & 24,883 & 57,689 & 1.55 & $1.33-1.81$ & 32.01 & $<0.01$ \\
\hline$\geq 80$ & Yes & 205 & 168 & & & & \\
\hline & No & 15,228 & 22,985 & 1.84 & $1.50-2.26$ & 35.13 & $<0.01$ \\
\hline ILD & & & & & & & \\
\hline $20-29$ & Yes & 0 & 0 & & & & \\
\hline & No & 108 & 83 & & & & \\
\hline 30-39 & Yes & 0 & 0 & & & & \\
\hline & No & 254 & 271 & & & & \\
\hline
\end{tabular}


Table 3. Continued

\begin{tabular}{|c|c|c|c|c|c|c|c|}
\hline Group & & Women (n) & Men (n) & $\mathrm{OR}$ & $95 \% \mathrm{Cl}$ & $\chi^{2}$ & $P$-value \\
\hline & No & 653 & 271 & 0.41 & $0.05-2.96$ & 0.81 & 0.36 \\
\hline & No & 1,542 & 1,918 & 1.06 & $0.35-3.17$ & 0.01 & 0.90 \\
\hline \multirow[t]{2}{*}{$60-69$} & Yes & 12 & 24 & & & & \\
\hline & No & 1,941 & 3,974 & 1.02 & $0.51-2.05$ & 0.00 & 0.94 \\
\hline & No & 2,450 & 4,684 & 1.55 & $0.95-2.51$ & 3.20 & 0.07 \\
\hline \multirow[t]{2}{*}{$80+$} & Yes & 11 & 19 & & & & \\
\hline & No & 1,128 & 1,446 & 0.74 & $0.35-1.56$ & 0.61 & 0.43 \\
\hline
\end{tabular}

Between January 2013 and December 2013. Summarized based on the diagnosis at the top of the list of the International Statistical Classification of Diseases and Related Health Problems, 10th edition (ICD-10) codes of respiratory diseases.

$\mathrm{PE}$, pulmonary embolism; $\mathrm{OR}$, odds ratio; $\mathrm{Cl}$, confidence intervals; ILD, interstitial lung disease; $\mathrm{COPD}$, chronic obstructive pulmonary disease; $\mathrm{RA}$, rheumatoid arthritis.

were recorded as having both DVT and PE were regarded as PE cases. The presence of VTE was validated based on simultaneous anticoagulation at the time of the diagnosis.

Analysis

We calculated the prevalence rates based on the number of patients diagnosed with RA, ILD or COPD, in 2013. The $95 \%$ confidence intervals (CIs) were calculated using the normal approximation to the binomial distribution. A $\chi^{2}$ test was used to compare frequencies of DVT and PE between men and women. $P<0.05$ was considered statistically significant. All the analyses were conducted using SAS version 9 (SAS Institute, Cary, NC, USA).

\section{Results}

Prevalence of DVT and PE

DVT was detected in $11,368(0.028 \%)$ of the cases, among those aged $\geq 20$ years. The prevalence of DVT was found to be 28.0 per 100,000 individuals in the general population, while in men with RA, it was 94.6 per 100,000 individuals; this is approximately 3.7 times higher than the prevalence in the general population. In addition, the prevalence rates of DVT in men with COPD and ILD were about 4 and 2.1 times, respectively, higher than those observed in men in the general population.

The prevalence of DVT in women with RA was found to be 67.7 per 100,000 individuals, which is approximately 2.2 times higher than the incidences observed in the general population. The prevalence rates of the same, in women with COPD and ILD, were about 8 and 5 times, respectively, higher than those in women in the general population (Table 1).

PE was detected in $11,368(0.015 \%)$ of the cases, among those aged $\geq 20$ years. The prevalence of PE was found to be 15.5 per 100,000 individuals in the general population, while that of men with RA was 88.7 per 100,000 individuals; this is approximately 6.7 times higher than the prevalence observed in the general population. In addition, the prevalence rates of PE in men with COPD and ILD were about 20.8 and 27.5 times, respectively, higher than those observed in men in the general population.

The prevalence of PE in women with RA was found to be 62.2 per 100,000 individuals, which is approximately 3.4 times higher than the incidence observed in the general population. The prevalence rates of PE in women with COPD and ILD were about 39 and 37 times, respectively, higher than those observed in women in the general population (Table 1).

Risk of DVT and PE, between men and women

The prevalence of DVT was not statistically different between women and men with RA. However, the prevalence of DVT in women with COPD, ILD, or general population was 2.4, 2.7, 1.2 times significantly higher than those observed in men, respectively (Table 2). The prevalence of PE in women with RA was lower than the corresponding prevalence in men. However, the prevalence of PE in women with COPD, ILD, or general population was 2.5, 1.8, 1.3 times, significantly higher than those observed in men, respectively (Table 2).

Risk of DVT and PE, stratified by age

The prevalence of DVT in women with general population was significantly higher than men at the age between 50 and 79 years (Table 3). Among COPD, women were significantly higher than men the age above 50's, while significance was observed only in 70's patients with ILD.

The prevalence of PE in women with general population was significantly higher than men at the age between 60 and 79 years (Table 4). However, the prevalence of PE in women with general population was significantly lower than men at the age of 30's and 50's (Table 4). Among COPD, women were significantly higher than men the age above 60's, while significance was observed only in 70 's patients with ILD.

\section{Discussion}

The present population-based study provides new data which supports the association between chronic lung diseases and sex in the prevalence of VTE. Risk of DVT in women had a 0.71-fold lower with men RA. Risk of DVT in women had a 2.41, 2.75-fold higher than men with COPD, ILD respectively. Risk of PE in women had a 0.70 -fold lower than men with RA. Risk of PE in women had a 2.57 (95\% CI, 2.25-2.93), 1.85-fold higher men with COPD and ILD, respectively. This study shows sex is an important determinant of venous thromboembolism prevalence in relation to underlying 
Table 4. Risk of age and sex in pulmonary embolism prevalence in the Korean national population in general population and patients with interstitial lung disease, chronic obstructive pulmonary disease, and rheumatoid arthritis

\begin{tabular}{|c|c|c|c|c|c|c|c|}
\hline \multicolumn{2}{|l|}{ Group } & Women (n) & Men (n) & OR & $95 \% \mathrm{Cl}$ & $\chi^{2}$ & $P$-value \\
\hline \multicolumn{8}{|c|}{ General population } \\
\hline \multirow[t]{2}{*}{$20-29$} & Yes & 41 & 68 & & & & \\
\hline & No & $3,209,340$ & $3,557,168$ & 0.66 & $0.45-0.98$ & 4.21 & 0.04 \\
\hline \multirow[t]{2}{*}{$30-39$} & Yes & 105 & 156 & & & & \\
\hline & No & $3,969,404$ & $4,178,011$ & 0.70 & $0.55-0.90$ & 7.52 & $<0.01$ \\
\hline \multirow[t]{2}{*}{$40-49$} & Yes & 202 & 215 & & & & \\
\hline & No & $4,399,916$ & $4,554,297$ & 0.97 & $0.80-1.17$ & 0.08 & 0.77 \\
\hline \multirow[t]{2}{*}{$50-59$} & Yes & 321 & 388 & & & & \\
\hline & No & $3,995,611$ & $4,045,446$ & 0.83 & $0.72-0.97$ & 5.52 & 0.01 \\
\hline \multirow[t]{2}{*}{$60-69$} & Yes & 707 & 576 & & & & \\
\hline & No & $2,305,032$ & $2,160,164$ & 1.15 & $1.03-1.28$ & 6.23 & 0.01 \\
\hline \multirow[t]{2}{*}{ 70-79 } & Yes & 1,420 & 868 & & & & \\
\hline & No & $1,764,280$ & $1,289,843$ & 1.19 & $1.09-1.30$ & 17.29 & $<0.01$ \\
\hline \multirow[t]{2}{*}{$\geq 80$} & Yes & 875 & 368 & & & & \\
\hline & No & 816,231 & 342,121 & 0.99 & $0.88-1.12$ & 0.00 & 0.95 \\
\hline \multicolumn{8}{|l|}{ RA } \\
\hline \multirow[t]{2}{*}{$20-29$} & Yes & 0 & 0 & & & & \\
\hline & No & 1,599 & 292 & & & & \\
\hline \multirow[t]{2}{*}{ 30-39 } & Yes & 0 & 1 & & & & \\
\hline & No & 6,191 & 976 & & & & \\
\hline \multirow[t]{2}{*}{$40-49$} & Yes & 4 & 2 & & & & \\
\hline & No & 14,066 & 2,418 & 0.34 & $0.06-1.87$ & 1.66 & 0.19 \\
\hline \multirow[t]{2}{*}{$50-59$} & Yes & 5 & 3 & & & & \\
\hline & No & 23,439 & 4,733 & 0.33 & $0.08-1.40$ & 2.45 & 0.11 \\
\hline \multirow[t]{2}{*}{$60-69$} & Yes & 19 & 6 & & & & \\
\hline & No & 18,136 & 5,234 & 0.91 & $0.36-2.28$ & 0.03 & 0.84 \\
\hline \multirow[t]{2}{*}{$70-79$} & Yes & 37 & 10 & & & & \\
\hline & No & 11,314 & 3,620 & 1.18 & $0.58-2.38$ & 0.22 & 0.63 \\
\hline \multirow[t]{2}{*}{$\geq 80$} & Yes & 12 & 2 & & & & \\
\hline & No & 2,145 & 590 & 1.65 & $0.36-7.39$ & 0.43 & 0.50 \\
\hline \multicolumn{8}{|l|}{ COPD } \\
\hline \multirow{2}{*}{$20-29$} & Yes & 0 & 0 & & & & \\
\hline & No & 1,016 & 994 & & & & \\
\hline \multirow[t]{2}{*}{ 30-39 } & Yes & 2 & 4 & & & & \\
\hline & No & 1,972 & 2,238 & 0.56 & $0.10-3.10$ & 0.43 & 0.50 \\
\hline $40-49$ & Yes & 11 & 9 & & & & \\
\hline & No & 4,110 & 5,505 & 1.63 & $0.67-3.95$ & 1.22 & 0.26 \\
\hline 50-59 & Yes & 24 & 48 & & & & \\
\hline & No & 10,924 & 18,868 & 0.86 & $0.52-1.41$ & 0.34 & 0.55 \\
\hline 60-69 & Yes & 84 & 128 & & & & \\
\hline & No & 15,863 & 41,907 & 1.73 & $1.31-2.28$ & 15.67 & $<0.01$ \\
\hline 70-79 & Yes & 267 & 315 & & & & \\
\hline & No & 24,890 & 57,783 & 1.96 & $1.67-2.31$ & 68.15 & $<0.01$ \\
\hline$\geq 80$ & Yes & 186 & 152 & & & & \\
\hline & No & 15,247 & 23,001 & 1.84 & $1.48-2.28$ & 32.11 & $<0.01$ \\
\hline ILD & & & & & & & \\
\hline $20-29$ & Yes & 0 & 0 & & & & \\
\hline & No & 108 & 83 & & & & \\
\hline 30-39 & Yes & 0 & 0 & & & & \\
\hline & No & 254 & 271 & & & & \\
\hline
\end{tabular}


Table 4. Continued

\begin{tabular}{|c|c|c|c|c|c|c|c|}
\hline Group & & Women (n) & Men (n) & $\mathrm{OR}$ & $95 \% \mathrm{Cl}$ & $\chi^{2}$ & $P$-value \\
\hline \multirow[t]{2}{*}{$40-49$} & Yes & 2 & 3 & & & & \\
\hline & No & 653 & 631 & 0.64 & $0.10-3.86$ & 0.23 & 0.62 \\
\hline \multirow[t]{2}{*}{$50-59$} & Yes & 5 & 1 & & & & \\
\hline & No & 1,543 & 1,924 & 6.23 & $0.72-53.42$ & 3.65 & 0.05 \\
\hline \multirow[t]{2}{*}{$60-69$} & Yes & 12 & 21 & & & & \\
\hline & No & 1,941 & 3,977 & 1.17 & $0.57-2.38$ & 0.18 & 0.66 \\
\hline \multirow[t]{2}{*}{$70-79$} & Yes & 29 & 32 & & & & \\
\hline & No & 2,451 & 4,689 & 1.73 & $1.04-2.87$ & 4.67 & 0.03 \\
\hline \multirow[t]{2}{*}{$80+$} & Yes & 14 & 17 & & & & \\
\hline & No & 1,125 & 1,448 & 1.06 & $0.52-2.15$ & 0.02 & 0.87 \\
\hline
\end{tabular}

Between January 2013 and December 2013. Summarized based on the diagnosis at the top of the list of the International Statistical Classification of Diseases and Related Health Problems, 10th edition (ICD-10) codes of respiratory diseases.

$\mathrm{OR}$, odds ratio; $\mathrm{Cl}$, confidence intervals; ILD, interstitial lung disease; COPD, chronic obstructive pulmonary disease; RA, rheumatoid arthritis

disease.

The previous study suggested the incidence of first PE and DVT between men and women was similar, but recurrence of PE and DVT in men was higher than women. ${ }^{1,4,13}$ However, women was a higher prevalence of VTE than men in general population in Korea. In DVT, except at the age of 70's, DVT prevalence of women was lower than men (Table 3). The prevalence of PE was higher in women than men between 60 and 79 years (Table 3). Until the age of 60 's, the prevalence of DVT and PE was lower in women than men in general population in Korea. This study showed aged population between 60 to 79 years mainly contribute to sex difference prevalence of VTE in Korea.

The prevalence of DVT in COPD was significantly higher in women than men above 60 years. It was found that women with COPD who were in the low smoking exposure group were associated with lower lung function than men with COPD. ${ }^{14}$ This may partially explain why women with COPD are more susceptible to developing PE than men. However, it is not well-explained risk DVT of women is higher than men in COPD. We may pay attention to VTE development in aged women with COPD.

ILD is more prevalent in men than women in the present study. ILD is also considered more susceptible in men than women. Women with ILD was a higher prevalence of PE than men at the age of 70 's. Although there is no significant difference between men and women in the prevalence of DVT in the age of 70's, tendency to higher prevalence in women than men. The previous study also showed men (odds ratio 0.96, 95\% CI 0.96-0.99) was lower risk of VTE than women in patients with pulmonary fibrosis. ${ }^{15}$
In contrast to COPD and ILD, sex may not influence on the prevalence of DVT or PE between women and men in all age groups in this study. The previous study also showed rate VTE was similar between men and women with rheumatoid arthritis. ${ }^{16}$

The HIRA database provided only limited patient data pertaining to age, sex, year, diagnostic codes, and medication codes. Therefore, we were unable to validate patients through the identification or exclusion of the definition, through a review of the source medical records. According to the definition of COPD defined by the Health Insurance Review and Assessment Agency, some COPD ICD-10 codes in the present study are missing and the number of COPD patients is considered to be reduced. Another limitation was that we could not investigate the risk factors associated with taking female hormones or menopause. The severity of the condition of patients with VTE was not evaluated due to limited access to individual medical records. However, this large-scale data may provide new insights into the prevalence of PE in men and women with COPD and ILD.

In conclusion, our study suggests that the prevalence rates of PE and DVT in women were significantly higher than those in men, among patients with COPD and ILD, while the prevalence rates of $\mathrm{PE}$ and DVT in the cases of RA were not significantly different, between men and women. Therefore, attention should be paid to the development of PE and DVT, especially in women with COPD or ILD.

\section{Conflicts of interest}

The authors have no conflicts of interest to declare.

\section{References}

1. Spencer FA, Emery C, Lessard D, Anderson F, Emani S, Aragam J, et al. The Worcester Venous Thromboembolism study: a population-based study of the clinical epidemiology of venous thromboembolism. Journal of General Internal Medicine 2006;21:722-7.

2. Lee CH, Lin LJ, Cheng CL, Kao Yang YH, Chen JY, Tsai LM. Incidence and cumulative recurrence rates of venous thromboembolism in the Taiwanese population. Journal of thrombosis and haemostasis: JTH 2010;8 1515-23.
3. Nordstrom M, Lindblad B, Bergqvist D, Kjellstrom T A prospective study of the incidence of deep-vein thrombosis within a defined urban population. Journal of Inernal Medicine 1992;232:155-60.

4. Roach RE, Lijfering WM, Rosendaal FR, Cannegieter SC, le Cessie S. Sex difference in risk of second but not of first venous thrombosis: paradox explained. Circulation 2014;129:51-6.

5. Oger E. Incidence of venous thromboembolism: a community-based study in Western France. EPI-GETBP Study Group. Groupe d'Etude de la Thrombose de Bretagne Occidentale. Thrombosis and Haemostasis 2000; 83:657-60.
6. McRae S, Tran H, Schulman S, Ginsberg J, Kearon C. Effect of patient's sex on risk of recurrent venous thromboembolism: a meta-analysis. Lancet (London, England) 2006;368:371-8.

7. Anderson FA, Jr., Spencer FA. Risk factors for venous thromboembolism. Circulation 2003;107(23 Suppl 1): I9-16.

8. Heit JA, Silverstein MD, Mohr DN, Petterson TM, O'Fallon WM, Melton LJ 3rd. Risk factors for deep vein thrombosis and pulmonary embolism: a population-based case-control study. Archives of Internal Medicine 2000;160:809-15.

9. Sorheim IC, Johannessen A, Gulsvik A, Bakke PS, Sil- 
verman EK, DeMeo DL. Gender differences in COPD: are women more susceptible to smoking effects than men? Thorax 2010;65:480-5.

10. Carey MA, Card JW, Voltz JW, Arbes SJ Jr, Germolec DR, Korach KS, et al. It's all about sex: gender, lung development and lung disease. Trends in endocrinology and metabolism: TEM 2007;18:308-13.

11. Kim DS. Introduction: health of the health care system in Korea. Soc Work Public Health 2010;25:127-41.

12. Kim DS. Special issue on the national health care sys- tem of South Korea. Soc Work Public Health 2010;25: 125-6.

13. Kyrle PA, Minar E, Bialonczyk C, Hirschl M, Weltermann A, Eichinger S. The risk of recurrent venous thromboembolism in men and women. The New England Journal of Medicine 2004;350:2558-63.

14. Sørheim IC, Johannessen A, Gulsvik A, Bakke PS, Silverman EK, DeMeo DL. Gender differences in COPD: are women more susceptible to smoking effects than men? Thorax 2010;65:480-5.
15. Sprunger DB, Olson AL, Huie TJ, Fernandez-Perez ER, Fischer A, Solomon JJ, et al. Pulmonary fibrosis is associated with an elevated risk of thromboembolic disease. The European Respiratory Journal 2012;39: 125-32.

16. Holmqvist ME, Neovius M, Eriksson J, Mantel A, Wallberg-Jonsson S, Jacobsson LT, et al. Risk of venous thromboembolism in patients with rheumatoid arthritis and association with disease duration and hospitalization. JAMA 2012;308:1350-6. 